\title{
Trained Immunity-Based Vaccines: A New Paradigm for the Development of Broad-Spectrum Anti-infectious Formulations
}

\author{
Silvia Sánchez-Ramón ${ }^{1,2 \star}$, Laura Conejero ${ }^{3}$, Mihai G. Netea ${ }^{4,5}$, David Sancho ${ }^{6}$, \\ Óscar Palomares ${ }^{7}$ and José Luis Subiza ${ }^{3}$
}

${ }^{1}$ Department of Clinical Immunology and IdISSC, Hospital Clínico San Carlos, Madrid, Spain, ${ }^{2}$ Department of Immunology, ENT and Ophthalmology, Complutense University School of Medicine, Madrid, Spain, ${ }^{3}$ Inmunotek, Alcalá de Henares, Spain, ${ }^{4}$ Department of Internal Medicine and Radboud Center for Infectious Diseases, Radboud University Medical Center, Nijmegen, Netherlands, ${ }^{5}$ Department for Genomics and Immunoregulation, Life and Medical Sciences Institute, University of Bonn, Bonn, Germany, ${ }^{6}$ Immunobiology Laboratory, Centro Nacional de Investigaciones Cardiovasculares, Madrid, Spain,

${ }^{7}$ Department of Biochemistry and Molecular Biology, School of Chemistry, Complutense University of Madrid, Madrid, Spain

OPEN ACCESS

Edited by:

Pedro A. Reche

Complutense University of Madrid

Spain

Reviewed by:

Randy A. Albrecht,

Icahn School of Medicine at Mount

Sinai, United States

Michael Schotsaert,

Icahn School of Medicine at Mount

Sinai, United States

*Correspondence:

Silvia Sánchez-Ramón ssramon@salud.madrid.org

Specialty section:

This article was submitted to Vaccines and Molecular Therapeutics,

a section of the journal

Frontiers in Immunology

Received: 04 September 2018 Accepted: 29 November 2018

Published: 17 December 2018

Citation:

Sánchez-Ramón S, Conejero L, Netea MG, Sancho D, Palomares Ó and Subiza JL (2018) Trained Immunity-Based Vaccines: A New Paradigm for the Development of Broad-Spectrum Anti-infectious Formulations. Front. Immunol. 9:2936. doi: 10.3389/fimmu.2018.02936
Challenge with specific microbial stimuli induces long lasting epigenetic changes in innate immune cells that result in their enhanced response to a second challenge by the same or unrelated microbial insult, a process referred to as trained immunity. This opens a new avenue in vaccinology to develop Trained Immunity-based Vaccines (TIbV), defined as vaccine formulations that induce training in innate immune cells. Unlike conventional vaccines, which are aimed to elicit only specific responses to vaccine-related antigens, TlbV aim to stimulate broader responses. As trained immunity is generally triggered by pattern recognition receptors (PRRs), TIbV should be formulated with microbial structures containing suitable PRR-ligands. The TlbV concept we describe here may be used for the development of vaccines focused to promote host resistance against a wide spectrum of pathogens. Under the umbrella of trained immunity, a broad protection can be achieved by: (i) increasing the nonspecific effector response of innate immune cells (e.g., monocyte/macrophages) to pathogens, (ii) harnessing the activation state of dendritic cells to enhance adaptive $T$ cell responses to both specific and nonrelated (bystander) antigens. This capacity of TlbV to promote responses beyond their nominal antigens may be particularly useful when conventional vaccines are not available or when multiple coinfections and/or recurrent infections arise in susceptible individuals. As the set of PRR-ligands chosen is essential not only for stimulating trained immunity but also to drive adaptive immunity, the precise design of TlbV will improve with the knowledge on the functional relationship among the different PRRs. While the TlbV concept is emerging, a number of the current anti-infectious vaccines, immunostimulants, and even vaccine adjuvants may already fall in the TlbV category. This may apply to increase immunogenicity of novel vaccine design approaches based on small molecules, like those achieved by reverse vaccinology.

Keywords: adjuvants, innate immunity, immunostimulants, pattern recognition receptors (PRRs), PRR-ligands, trained immunity, trained immunity-based vaccines (TIbV), vaccines 


\section{BACKGROUND}

Conventional anti-infectious vaccines are primarily intended to target specific pathogens by enhancing an antigen-specific adaptive immune response. This response is based on triggering $\mathrm{B}$ and $\mathrm{T}$ lymphocytes that, by virtue of their clonally segregated antigen receptors, generate effector, and memory cells. Proliferation and differentiation of specific lymphocytes is the basis of immunological memory, a hallmark of the adaptive immune response and the rationale behind conventional vaccines. Louis Pasteur built on the work of Edward Jenner to develop the principles of using attenuated live microbes to prevent the pathogen's caused disease (1). Pre-exposure vaccination was a major breakthrough in the prevention of many infectious diseases. His rabies vaccine for post-exposure prophylaxis in the severely ill boy Joseph Meister in 1885 raised the concept of therapeutic vaccines (2).

Immunological adaptive memory has been traditionally defined as long-term acquired memory against an encountered antigen through infection or immunization, leading to a quicker and heightened immune response upon an ulterior rendezvous (3). Resting clones of memory $\mathrm{B}$ and $\mathrm{T}$ cells can survive at different compartments for several decades until reactivation by recall responses $(4,5)$. Recent epidemiological studies highlight the role of subclinical infections or repeated endemic exposure for the maintenance of protective antigen-specific antibodies and $\mathrm{T}$ cells, indicating the dependency of this adaptive memory on antigen-re-exposure $(6,7)$. Besides, the persistent specific $\mathrm{T}$ and B lymphocyte activation can also favor "infectious immunity," a process by which innate immune responses are enhanced by mechanisms depending on the persistence of the activation of adaptive immunity (3).

\section{Trained Immunity}

Importantly however, solid epidemiological data have also demonstrated that certain mild infections or vaccinations, such as with bacilli Calmette-Guerin (BCG), lead to protection against heterologous infections, with a strong impact on overall mortality due to infection for up to 1 year $(8-11)$. When vaccination against smallpox was introduced around 200 years ago, positive side-effects such as protection against measles, scarlet fever and whooping cough, among others, were noticed (12). These and many other clinical observations, pointed to a long-lasting nonspecific collateral benefit associated to these vaccines, regardless of specific priming and subsequent clonal selection of $\mathrm{T}$ and B lymphocytes specific for the nominal antigens present in the vaccine. In recent years, it has become evident that cells of the innate immunity may be primed upon encounter with certain pathogens or molecular patterns associated to pathogens (PAMPs), acquiring a higher resistance to a second infection against the same or unrelated pathogens (cross-protection) for a relatively long time $(13,14)$. This concept has been termed "trained (innate) immunity." Trained immunity implies adaptation of innate immunity processes in a de-facto innate immunological memory, and plays an essential role in vertebrates (15), which is similar to that described for bacteria, plants and invertebrates (16).
Mechanistically, trained immunity is defined by immunological, metabolic and epigenetic hallmarks (1720). Several studies have shown that metabolic reprogramming through a shift from oxidative phosphorylation to aerobic glycolysis (the Warburg effect) mediated by the Akt/mTOR/HIF$1 \alpha$ pathway is a key mechanism for trained immunity responses $(21,22)$. The glycolysis, glutaminolysis, and cholesterol synthesis pathways in monocytes and macrophages were identified as the essential underlying mechanism linking epigenetic rewiring and the induction of improved innate immunity $(22,23)$. Thus, changes in cellular metabolism influence the epigenetic reprogramming of innate immune cells having an impact on cytokine and reactive oxygen species' production. In this regard, trained immunity regulates epigenetic changes such as $\mathrm{H} 3 \mathrm{~K} 4$ trimethylation and $\mathrm{H} 3 \mathrm{~K} 27$ acetylation, both associated with active chromatin, and $\mathrm{H} 3 \mathrm{~K} 9$ trimethylation, a repressive marker $(19,22,24)$. Trained immunity favors the production and release of proinflammatory cytokines such as TNF- $\alpha$, IL-6 and IL-1 $\beta$ by innate immune cells upon exposure to a second stimulus $(14,24,25)$. Most of these features differ from what classically has been postulated for the innate immune system, as trained immunity induces functional reprogramming within innate immune cells that maintain these cells in a "ready-to-react" functional state over extended periods of time. Interestingly, although a maximum duration of trained immunity effects has been reported up to 3 months (24), a long lasting effect of trained cells with the capacity to enhance $\mathrm{T}$ cell responses up to 1 year is feasible (26), thus bridging innate training with adaptive responses. Moreover, the storage of specific long peptides for ulterior long-lasting cross-presentation to elicit cytotoxic $\mathrm{T}$ lymphocytes is an additional feature that may be associated to trained immunity in monocytes and could bridge innate and adaptive imprinting (27).

A striking example indicating a durable change within the innate immunity compartment is the imprinting of BCG on bone marrow hematopoietic stem cells and multipotent progenitors, giving rise to epigenetically modified macrophages that provide better protection against virulent $M$. tuberculosis than naïve macrophages (28). Unlike the classical memory following the adaptive immune response, long-term responses associated to trained immunity are not based on a clonal expansion of lymphocytes but on reprogramming myeloid cells by stable epigenetic changes (Table 1).

Pathogen recognition receptors (PRRs) expressed on innate immune cells, including long-lived macrophages and their precursors, are involved in the stimulation of trained immunity. Different PRRs have been involved in this task, such as C-type lectin receptors (CLRs) and Nod-like receptors (NLRs). Training of the innate immunity is therefore based on boosting nonspecific immunity to re-infection by bacteria, fungi or viruses by certain pathogen's derived components (19). There are many examples of pathogen-associated molecules with evidence of cross-protection in experimental models (Table 2). The increased host defense induced by trained immunity, while effective against a range of pathogens, is non-specific as it is mediated by the release of proinflammatory cytokines such as IL-1 $\alpha$ and TNF- $\alpha$ and/or reactive oxygen species (ROS) (17). The 
TABLE 1 | Similarities and differences between trained and adaptive immunity.

\begin{tabular}{|c|c|c|}
\hline Feature & Trained immunity & Adaptive immunity \\
\hline Specificity & \pm & +++ \\
\hline Inducers & $\begin{array}{l}\text { Pathogens and derived } \\
\text { products (PAMPs) }\end{array}$ & $\begin{array}{l}\text { Antigen presentation } \\
\text { plus costimulatory } \\
\text { signals and cytokines } \\
\text { from DCs }\end{array}$ \\
\hline Receptors & PRRs & $\begin{array}{l}\text { slg, TCR, receptors for } \\
\text { costimulation and } \\
\text { cytokines }\end{array}$ \\
\hline Clonality & No & Yes \\
\hline Cells & $\begin{array}{l}\text { Monocytes, } \\
\text { Macrophages, NK, } \\
\text { DCs, ILCs, and other } \\
\text { innate immune cells }\end{array}$ & B and T lymphocytes \\
\hline Memory & Months & Years \\
\hline Memory mechanism & $\begin{array}{l}\text { Epigenetic } \\
\text { modifications }\end{array}$ & $\begin{array}{l}\text { Clonal expansion and } \\
\text { differentiation }\end{array}$ \\
\hline
\end{tabular}

TABLE 2 | Examples of pathogen-associated molecules with experimental evidence of cross-protection.

\begin{tabular}{|c|c|c|c|}
\hline Component & Source & $\begin{array}{l}\text { Cross- } \\
\text { protection }\end{array}$ & References \\
\hline LPS (endotoxin) & $\begin{array}{l}\text { Most } \\
\text { Gram-negative } \\
\text { bacteria, such as } \\
\text { E. coli }\end{array}$ & $\begin{array}{l}\text { Staphylococcus } \\
\text { aureus }\end{array}$ & (29) \\
\hline $\begin{array}{l}\text { Peptidoglycan } \\
\text { component } \\
\text { muramyl dipeptide }\end{array}$ & Bacteria & Toxoplasma & (30) \\
\hline Flagellin & $\begin{array}{l}\text { Gram-negative } \\
\text { bacteria }\end{array}$ & $\begin{array}{l}\text { Gram-positive } \\
\text { bacterium } \\
\text { Streptococcus } \\
\text { pneumoniae }\end{array}$ & (31) \\
\hline & & Rotavirus & (32) \\
\hline $\mathrm{FimH}$ & E. coli & Influenza virus & (33) \\
\hline$\beta$-glucan & Fungi & $\begin{array}{l}\text { Staphylococcus } \\
\text { aureus } \\
\text { Streptococcus } \\
\text { pneumoniae. }\end{array}$ & (34) \\
\hline Chitin & Fungi & $\begin{array}{l}\text { Staphylococcus } \\
\text { aureus or } \\
\text { Escherichia coli }\end{array}$ & (35) \\
\hline $\begin{array}{l}\text { CpG } \\
\text { oligodeoxynucleotide }\end{array}$ & Bacteria, synthetic & $\begin{array}{l}\text { E. coli } \\
\text { Influenza virus }\end{array}$ & $\begin{array}{l}(36) \\
(37) \\
(38)\end{array}$ \\
\hline
\end{tabular}

role of IL-1 $\alpha$ in host resistance to infection and how TNF$\alpha$ protects against infections have been recently updated (39, 40). Higher resistance due to trained immunity does not mean however an absolute resistance to every type of second infection that, on the other hand, may be favored by facts beyond the innate immune response. This might account for why a natural infection, such as primary infection by influenza A virus, can result in bacterial pneumonia resulting from superinfection by Streptococcus pneumoniae or other bacterial strains.

\section{MOVING AHEAD CONVENTIONAL VACCINES: TRAINED IMMUNITY-BASED VACCINES (TIBV)}

The exploitation of the principles of trained immunity may result in a next generation of anti-infectious vaccines (41-43). Trained immunity-based vaccines (TIbV) may confer a broad protection far beyond to the nominal antigens they contain. By proper targeting of innate immune cells to stimulate trained immunity, both nonspecific and specific immune responses can be enhanced by TIbV. Such responses can also be driven against bystander pathogens encountered by the host during the window of trained immunity.

Vaccines using attenuated and/or inactivated pathogens may be examples of TIbV as long as they contain PAMPs able to trigger PRRs inducing trained immunity. Different PRR ligands have been described as trained immunity stimuli, like Candidaderived $\beta$-glucan or BCG-derived muramyl dipeptide, triggering CLRs (dectin-1) or NLRs (NOD2), respectively. Of note, by using these training stimuli, slight differences on how they modify the cellular metabolism of innate immune cells has been described (22). This opens the possibility that different trained immunity outcomes may be achieved varying the set of PRR ligands used in the TIbV. At this point, it should be noted that, within the context of a vaccine, the fact that trained innate immune cells may enhance adaptive responses is essential. In this regard, the role played by DCs, the cellular link between innate and adaptive immunity (44), must be pivotal. Although trained immunity is linked to innate cells such as monocytes, macrophages and NK cells (19), the trained immunity-promoting BCG vaccine can also enhance heterologous $T$ cell responses $(26,45,46)$. It has been speculated that the increased expression of certain PRR in innate trained cells, as well as the release of typical innate immunity cytokines, such as IL-1 $\beta$, contribute to enhance adaptive $\mathrm{T}$ cell responses (26). In this regard, the polybacterial sublingual vaccine MV130, which contains whole cell heat-inactivated bacteria, has been shown to enhance in vivo $\mathrm{T}$ cell responses to unrelated antigens, while priming DCs and inducing IL- $1 \beta$ release in vitro (47). DCs with high immunostimulatory properties that enhance adaptive immune responses via IL-1 $\beta$ release have been described (48). Moreover, the role of inflammasome-associated IL-1 family cytokines in delineating the adaptive immune responses is established regarding differentiation of Th17 cells and promoting effector functions of Th1 cells (49). Interestingly, these DCs are rendered "hyperactive" by releasing IL-1 $\beta$ in absence of cell death by virtue of an alternative inflammasome pathway modulated by certain TLR ligands of microbial origin, like LPS and peptidoglycans (49). Thus, strong adaptive immune responses may be stimulated by certain PRRs stimuli that may complement those inducing trained immunity.

One of the most interesting aspects of trained immunity is that innate immune cells maintain a primed functional state for a quite long period of time (50). As it may last more than several months (26), the enhanced immune responses induced by a given TIbV may also be applied to possible bystander pathogens encountered by the host during this time frame. Thus, 
another relevant aspect of TIbV is that they may promote both nonspecific and specific resistance to unrelated pathogens while trained immunity is still present. This may be of particular interest when co-infections with the pathogens included in the $\mathrm{TIbV}$ are likely, especially in the context of recurrent infections. Thus, under the umbrella of trained immunity, the TIbV concept emerges as a new paradigm of vaccines seeking to increase host resistance against a broad spectrum of pathogens.

With the above concepts in mind, the proposed term of TIbV can be applied for those anti-infectious vaccines composed of whole microorganisms or derived products that display the following features (Figure 1):

i) Composed of trained immunity inducers, i.e. certain PAMPs, in addition to pathogen specific antigens.

ii) Intended to be effective not only against the specific pathogens targeted by the vaccine, but also against heterologous pathogens.

In contrast to conventional vaccines, TIbV efficacy cannot be measured solely in terms of specific responses to the nominal antigens included in the vaccine. In this regard, the clinical outcome scored by lower infectious rates in particular clinical settings is necessary.

\section{Examples of Non-conventional Vaccines That Can be Ascribed as TIbV}

Vaccines that may fall in the category of TIbV include those bacterial preparations used for recurrent infections for either the respiratory or urinary tract (51-53). Previous and recent studies provide many clinical observations that combinations of inactivated bacterial vaccines induce cross-protection against infections produced by quite different microorganisms $(41,54)$. In the case of the sublingual vaccine MV130, designed to prevent recurrent respiratory tract infections, a significant reduction in patient's rate of infection was observed (51). Besides inducing specific T cell immunity against the bacteria included in MV130, treated patients showed an enhancement in $\mathrm{T}$ cell response to unrelated flu antigens (51). MV130 triggers TLR and NLR signaling pathways on DCs releasing trained immunity hallmark cytokines (TNF $\alpha$, IL-6, and IL-1 $\beta$ ) (47). In addition, MV130

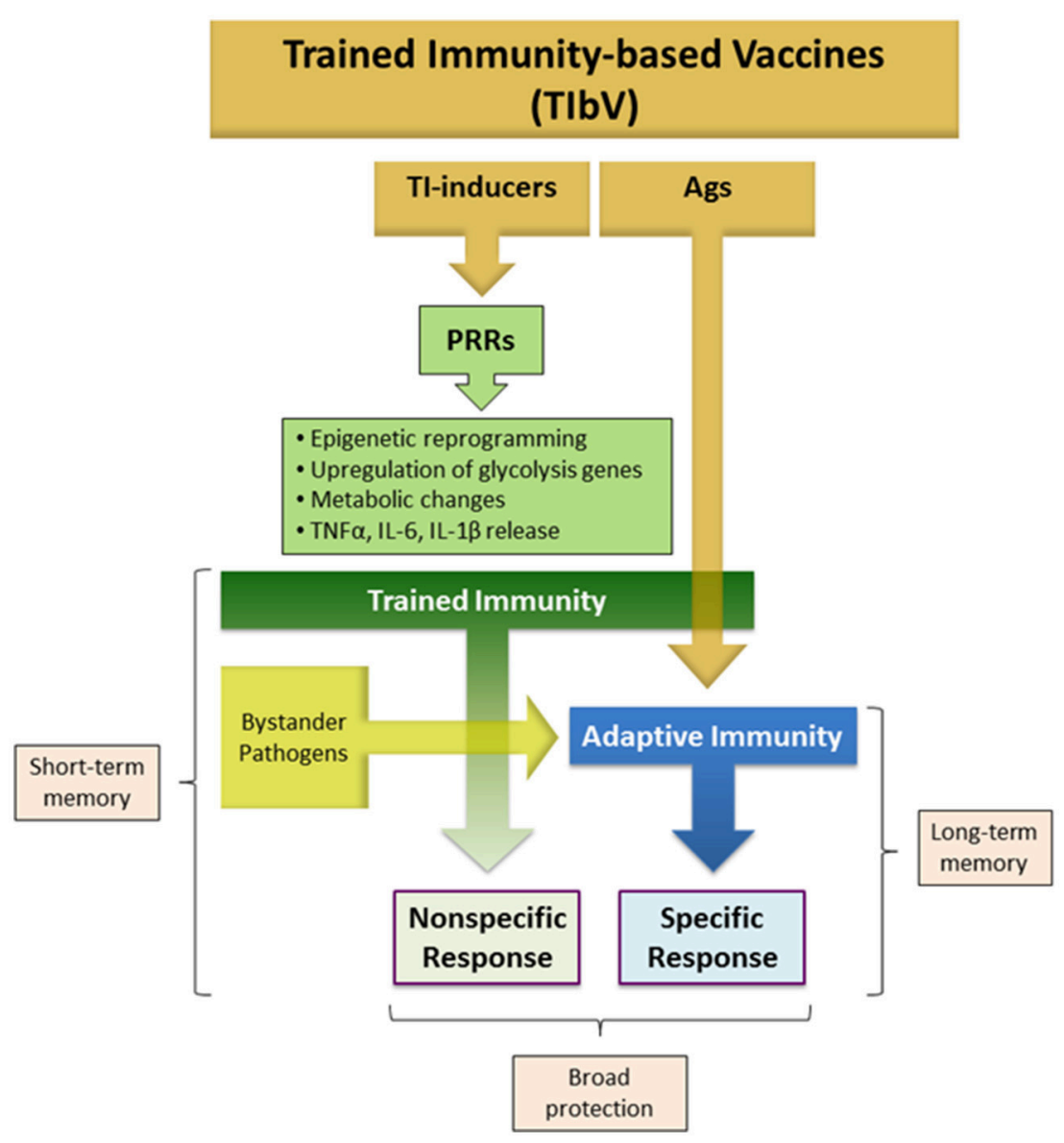

FIGURE 1 | Trained immunity-based vaccine components. TIbV consist of two essential components: (a) Trained immunity (TI) inducers: a range of PAMPs that target a variety of PRRs triggering different signaling pathways that mediate trained immunity. (b) TlbV-related Ags: the antigens associated with the pathogens acting as TI-inducers to which an adaptive immunity is aimed. Thus, TlbV are characterized by conferring Ag-nonspecific resistance directly dependent on trained immunity stimulation plus an Ag-specific resistance dependent on adaptive immunity against the TlbV components and eventual bystander pathogens. PAMP, pathogen-associated molecular pattern; PRR, pattern recognition receptor; Ag, antigen. 
promoted the generation of Th1 and Th17 responses with high levels of IL-10 both in vitro and in vivo to MV130-related and bystander antigens (47). A recent clinical trial performed in children with recurrent wheezing attacks (mostly of viral etiology) has shown the clinical benefit of MV130 as well as the protection in experimental models of respiratory viral infections by trained immunity mechanisms (Nieto et al., manuscript in preparation). Similarly, MV140 another sublingual whole cell heat-inactivated bacterial vaccine designed to prevent recurrent urinary tract infections $(52,53,55)$, was also effective against urobacteria species not included in its composition (53). MV140 also triggers the release of TNF $\alpha$, IL- 6 and IL- $1 \beta$ by DCs, albeit using different signaling pathways from MV130, and induces Th1 and Th17 responses by mechanisms mediated by CLRs and TLRs as well (56). Thus, both MV130 and M140 vaccines induce the release of a similar set of cytokines ascribed to trained immunity, and favor heterologous Th1 and Th17 responses in vivo as described for vaccines stimulating trained immunity (26). Figure 2 summarizes the proposed action mechanisms of either MV130 or MV140 as putative TIbV. Other bacterial preparations used as nonspecific immunostimulants may also act as trained immunity inducers (see below).

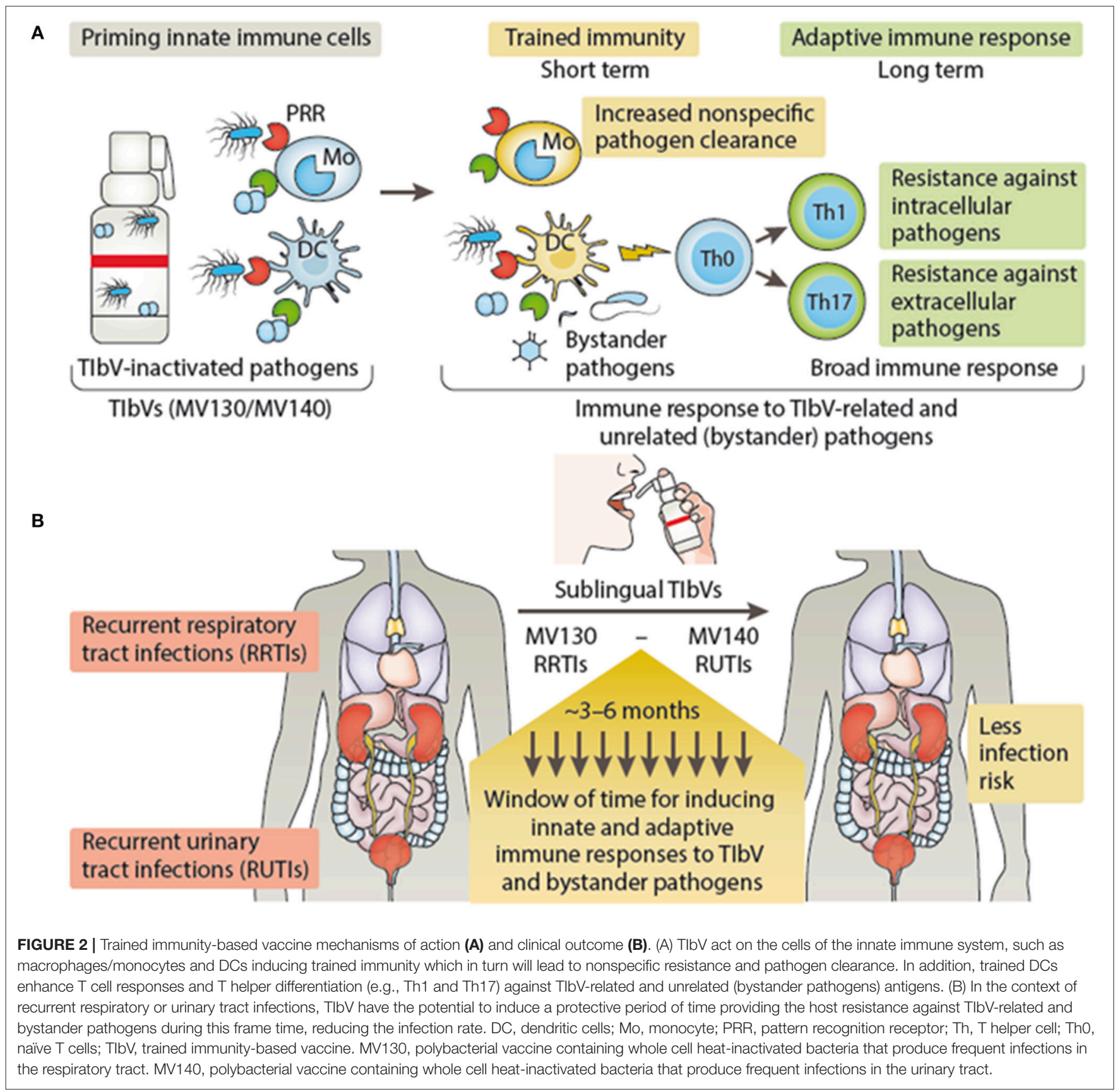




\section{Conventional Vaccines With Associated Trained-Immunity Effects as Potential TIbV}

A number of conventional anti-infectious vaccines, most of them containing live-attenuated pathogens, have been shown to induce, in addition to the intended specific memory, broad protection by nonspecific mechanisms $(46,58)$. Therefore, they can be considered within the category of TIbV provided that such mechanisms are related to trained immunity. If this were the case, harnessing innate memory as part of a vaccination strategy with these vaccines may be considered.

\section{BCG}

As above mentioned, most studies that examinated and elucidated the mechanisms of trained immunity have been performed with BCG as a model. Randomized-controlled trials carried out in Guinea-Bissau with low-birth-weight infants early vaccinated against tuberculosis with BCG, demonstrated clear beneficial effects reducing all-cause mortality, especially due to neonatal sepsis, respiratory infections, and fever (9). The effects of neonatal BCG vaccination on $\mathrm{T}$ and $\mathrm{B}$ lymphocytes subsets in infants in Denmark showed limited impact though (57) and did not affect parent-reported infections (59). It is not known whether the clinical setting in different populations, exposed to a high vs. low rate of pathogens, might account for these divergent outcomes. Recently, Arts et al. have demonstrated that BCG vaccination confers protection against viral infection (25). In a placebo-controlled clinical trial with BCG, all volunteers received the yellow fever vaccine 1 month after BCG, as an experimental mild viral infection. BCG-vaccinated volunteers displayed a significant reduction of viremia compared to the placebo group, which highly correlated with enhanced IL-1 $\beta$ production (25). In some experimental models of virus infection BCG immunization has been reported to confer non-specific protection; yet not in all, pointing out that the route and dose of BCG administration may be important (60).

BCG is currently used as local immunotherapy in bladder cancer (61). Interestingly, Buffen and cols. have demonstrated that the anticancer effects of BCG were dependent on trained immunity (62). In addition to a nonspecific cytotoxic effect for tumor cells by BCG-trained innate cells, these may enhance tumor specific $\mathrm{T}$ cell responses as a massive accumulation of tumor specific $\mathrm{T}$ lymphocytes are recovered in urine after successful BCG therapy (63). As endogenous tumor antigens may act as bystander antigens under the umbrella of trained immunity, this opens the possibility of TIbV as immunostimulants outside of anti-infectious purposes, e.g., tumor immunotherapy. In fact, pioneer studies of William Coley in cancer immunotherapy were based on administering bacterial products to cancer patients (64).

\section{Vaccinia Virus}

Live vaccinia virus was successfully used against smallpox until its eradication in 1977. Two observational studies carried out in Africa concluded that adults being smallpox vaccinated had significantly lower mortality risk, with a stronger effect observed in women than in men $(65,66)$. Since both studies were carried out when smallpox was already eradicated and, therefore, in the absence of the targeted infection, the beneficial effects are necessarily non-specific. The capacity of a subset of NK cells to exhibit certain aspects of innate memory following infection with vaccinia virus was found by Gillard et al. in 2011. They demonstrated that this innate memory provides host protection against a subsequent systemic infection with a lethal dose of vaccinia virus, in some cases resulting in the complete clearance of detectable virus (67).

\section{Influenza Vaccine}

Trivalent live attenuated influenza vaccine has been shown to confer indirect protection from respiratory illness among children (68).

Respiratory syncytial virus (RSV) and influenza virus share common features, including innate immunity activation via PRRs, such as TLR3, TLR7, and retinoic acid-inducible gene I (RIG-I) $(69,70)$. The cold-adapted, live attenuated influenza vaccine (CAIV) has been shown to provide non-specific crossprotection against RSV in a murine model of infection (71). The results demonstrated that this vaccination induces local immune responses that provide a broad range of antiviral immunity, including protection against RSV, and that TLR3- and TLR7mediated innate immunity plays an important role in protection against RSV (71).

\section{Immunostimulants and Adjuvants as Putative TIbV}

In addition to the examples described above, it is likely that other bacteria, fungi and viral preparations used as immunostimulants for different conditions might promote trained immunity if containing suitable inducers. In this regard, Candida-derived $\beta$ glucan is a paradigmatic example as it is a well-known inducer of trained immunity via dectin-1 (14). At this point, it should be noted that trained immunity-based immunostimulants might be considered within the TIbV concept because, under the umbrella of trained immunity, they may enhance innate and adaptive responses to bystander pathogens and their corresponding antigens (Figure 3A).

In 1986, Bistoni et al. demonstrated that systemic infection of mice with an avirulent $C$. albicans strain conferred protection not only against subsequent intravenous challenge with a pathogenic C. albicans strain but to $S$. aureus as well (72). More recently, it has been shown that protection from secondary lethal infection can be achieved with $\beta$-glucan and is dependent on epigenetic reprogramming linked to trained immunity (14). Although the immunostimulating effect of $\beta$-glucans is known for decades (73), the molecular mechanisms involved has started to be understood in the last few years $(19,21)$. The potential of oral $\beta$-glucan as "immune trainer" has been assayed in a pilot study in healthy volunteers (74). Innate immune responses were subsequently evaluated in peripheral blood mononuclear cells re-stimulated in vitro with $C$. albicans. However, the results showed a lack of cytokine production or microbicidal activity, which could be due to several reasons, including the dose and route of administration (74).

The immunostimulant OM-85 is a mixture of bacterial lysates for oral administration able to increase protection in 


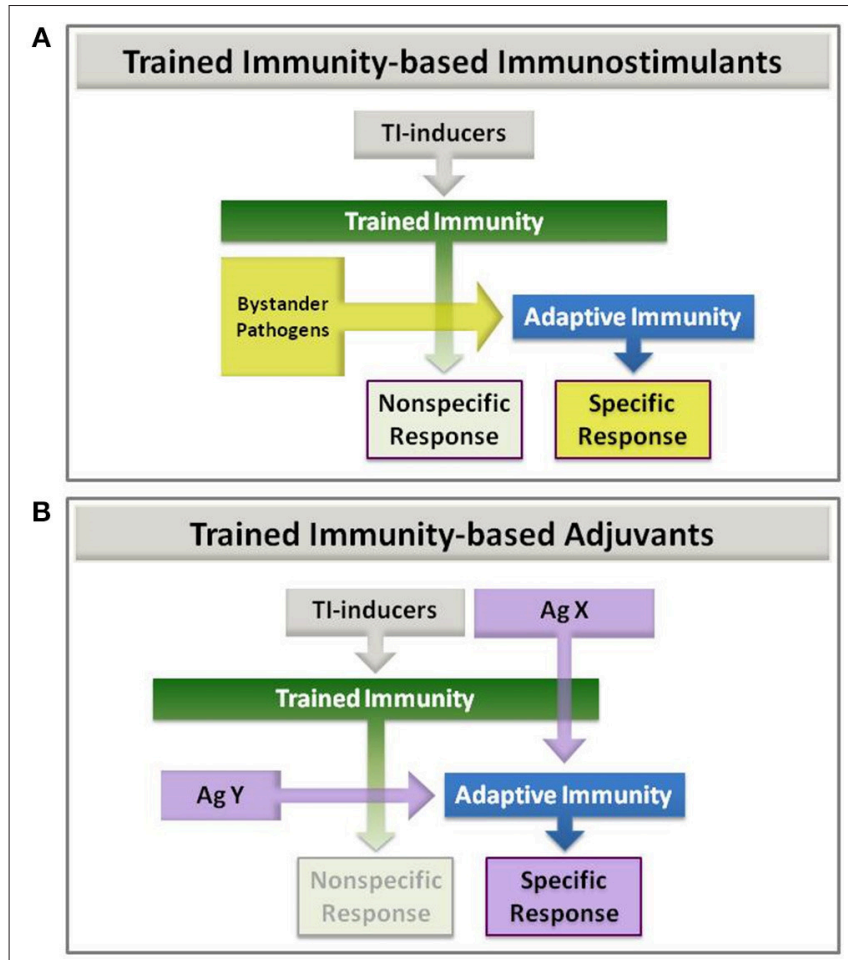

FIGURE 3 | Trained Immunity-based Immunostimulants (A) and Adjuvants (B). (A) Immunostimulants: trained immunity (TI) inducers that enhance both nonspecific and adaptive immune responses to eventual bystander pathogens. (B) Adjuvants: trained immunity (TI) inducers that are combined with an antigen. This latter can be co-delivered with the TI-inducers in the same vaccine $(\mathrm{AgX})$, or later on (AgY) in a two-step process, once trained immunity has been achieved.

a murine model of respiratory viral infection, reducing viral load in the lung following experimental infection (75). It also reduced rhinovirus infection of lung epithelial cells (76) and had a protective role in models of viral/bacterial respiratory infections, reducing disease symptoms and improving survival (77). OM-85 has demonstrated clinical efficacy reducing the incidence, prevalence and/or duration of infections in children and adults (78-80). It is not known whether the mechanisms behind crossprotection of this and similar immunostimulants are dependent on trained immunity, but it is likely in analogy with the bacterial vaccines described above.

Another aspect of trained immunity-based immunostimulants is that they might be considered adjuvants when combined with other antigens to which an enhanced immune response is expected (Figure 3B; AgX). Thus, TIbV containing exogenous or chimeric antigens can be furnished. This possibility has been recently described for BCG being used as adjuvant for recombinant hepatitis B surface antigen vaccination (rHBsAg) (81). Even if the antigen may be administered in a second step once the trained immunity is induced (Figure 3B; $\mathrm{AgY}$ ). In this composition the TIbV is split in two separated elements, the trained immunity-inducer and the antigen itself. In this sense, the influence of BCG on antibody and cytokine responses to human neonatal vaccination has been described already (82). Either combination can be used for the development of novel vaccines with very specific but low antigenic molecules such as those synthetic peptides designed by reverse vaccinology.

\section{CLINICAL APPLICATIONS OF TIBV}

The development of TIbV may represent an advantage over conventional vaccines in certain settings. Under the trained immunity umbrella, broader and stronger immune responses may be expected, without the limitations of antigen specificity. Some applications include the following:

1. When conventional vaccines are not available for pathogens that produce recurrent infections, such as those responsible for many of the respiratory and urinary infections, the most common infections in humans $(83,84)$. At this point, it is interesting to remark that during the 1918 influenza pandemic outbreak (Spanish flu), bacterial vaccines were used for preventive purposes with quite surprising success given the viral nature of the infection. Although this observation may be explained by a mere prevention of secondary infections of S. pneumoniae, which was included in many of those vaccines (85), a non-mutually exclusive alternative might be that they were acting by inducing trained immunity, i.e., as TIbV, truly protecting from flu infection.

2. To prevent illness in which bacteria and virus co-infections have a role, such as asthma exacerbations (86).

3. When directed to pathogens with high mutation rates, such as influenza virus $(87,88)$. The broad spectrum of TIbV may circumvent the selective pressure of highly specific vaccines. This may also be applied to avoid the emergence of new bacteria strains upon conventional vaccination as occurs with vaccines directed to specific pneumococcal serotypes (89).

4. When used for preventive purposes for individuals susceptible to infections for which there are no vaccines, i.e., children and elderly population which are susceptible to mucosal infections $(90,91)$. Also in certain immunodeficiency states in which innate immunity is often preserved. In this sense, TIbV might be an achievable alternative to the use of broad range of antibiotics for preventive purposes in recurrent infections $(92,93)$.

5. Restoring immune responsiveness in clinical conditions associated with immune paralysis, such as severe sepsis and/or malignant processes (94)

In addition, the TIbV concept can be applied to the design of vaccines directed to the antigen of interest whether it is combined or not with the trained immunity stimuli. As mentioned above this concept is also broad and TIbV may be considered immunostimulants for endogenous (bystander) pathogens, or as a type of adjuvant for any antigen. While all these applications are of primary clinical interest, caution is needed about the potential deleterious function of trained immunity in patients suffering diseases characterized by excessive inflammation. This potential deleterious effect of trained immunity could apply to atherosclerosis (95), cardiovascular events (96), gout (97), and a 
variety of autoimmune diseases and autoinflammatory disorders such as rheumatoid arthritis, systemic lupus erythematosus or hyper-IgD syndrome (98), where monocytes/macrophages show a detrimental trained immunity-like phenotype. Similarly, trained microglia has been linked to neurological disorders and stroke (99). Current knowledge, however, does not support such a deleterious role for TIbV: (a) Due to their nature, trained immunity is likely to have a transitory rather than a permanent effect, giving the system the required plasticity to avoid long-term potentially deleterious effects; (b) at least in two models (MV130 and MV140), TIbV have been shown to induce the production of the regulatory cytokine IL-10 by $\mathrm{DCs}$ and $\mathrm{T}$ cells, both in vitro and in vivo $(47,56)$; (c) MV130 has been shown to reduce recurrent infections in patients with rheumatoid arthritis without adverse effects (Candelas et al., manuscript in preparation), an observation also noted with other bacterial-derived immunostimulants (100, 101).

Many currently licensed vaccines consist of whole or inactivated pathogens; however, there has been a recent shift toward using simpler molecules such as highly purified antigens, recombinant, or synthetic peptides or DNA vaccines. Computational analysis of genetic sequences is now used for the prediction of just few T-cell epitopes fitting with most HLA molecules (102) as well as for antigen searching by the socalled reverse vaccinology (103). While these new generation of vaccines are focused to get a quite specific driven response, they are poorly immunogenic in absence of proper adjuvants. Thus, to confer protective immunity a strategy might be the combination of the adjuvant potential of trained immunity with the selected antigen epitopes. An important aspect to take into account is that it is not yet known whether or not all trained immunity stimuli produce the same functional behavior on innate immune cells with regard of driving $\mathrm{T}$ cells responses. As different PRR ligands may trigger different cell activation pathways with additive, synergies and opposite effects on key cell functions (44), it is likely that there are more than a single trained immunity functional program. Thus, the same antigen molecule can be eventually combined with different trained immunity stimuli for tailoring the better desired $\mathrm{T}$ cell response, like currently is being done with other adjuvants. In this regard, TLR8 agonists that mimic the immunomodulating effects of BCG, and enhance innate

\section{REFERENCES}

1. Smith KA. Louis pasteur, the father of immunology? Front Immunol. (2012) 3:68. doi: 10.3389/fimmu.2012.00068

2. Bourhy H, Perrot A, Cavaillon J-M. Rabies. Vaccines: A Biography. A. W. Arstentein. New York, NY: Springer-Verlag (2010). 73-85.

3. Farber DL, Netea MG, Radbruch A, Rajewsky K, Zinkernagel RM. Immunological memory: lessons from the past and a look to the future. Nat Rev Immunol. (2016) 16:124-8. doi: 10.1038/nri.2016.13

4. Pinna D, Corti D, Jarrossay D, Sallusto F, Lanzavecchia A. Clonal dissection of the human memory B-cell repertoire following infection and vaccination. Eur J Immunol. (2009) 39:1260-70. doi: 10.1002/eji.200839129

5. Smith SA, Zhou Y, Olivarez NP, Broadwater AH, de Silva AM, Crowe JE Jr. Persistence of circulating memory B cell clones with potential for dengue and adaptive immune responses have been described recently (104).

\section{FUTURE DIRECTIONS}

Much knowledge is required in this field to successfully develop the potential of TIbV. Although their main advantage is that they act broadly on different pathogens and their potential as novel immunotherapy approach in both infectious, and even non-infectious immune related diseases such as cancer immunotherapy is obvious, their extent and limitations may depend on their composition. The pattern of response induced in the host innate immune cells by the specific training stimulus may also dictate the duration and interaction with ongoing specific responses. Despite the beneficial effects of TIbV inducing trained immunity as a host defense mechanism, any possible harmful effect in the induction and/or maintenance of autoimmune disorders cannot be ruled out, irrespective that current evidence does not support such a deleterious role. More studies will have to be carried out to fully understand the advantages and limitations of TIbV. Moreover, the indication of TIbV might consider several factors such as drug intake (105) or diet (106) that may affect the induction of trained immunity or its activation status, respectively. Finally, trained immunitybased stimulants and/or adjuvants widen the spectrum of the insilico models for predicting immune responses. Thus, searching for new candidate combinations as trained immunity-based adjuvants for improved immunization purposes as TIbV is outlined as a novel and promising vaccine design.

\section{AUTHOR CONTRIBUTIONS}

SS-R, LC, and JS conducted literature searches, selected the studies, and wrote the manuscript. MN, DS, and ÓP critically contributed to the editing of the manuscript, final version and approval.

\section{ACKNOWLEDGMENTS}

We are grateful to Dr. Miguel Casanovas for helpful discussion. MN was supported by a Spinoza grant of the Netherlands Organization for Scientific Research. virus disease enhancement for decades following infection. J Virol. (2012) 86:2665-75. doi: 10.1128/JVI.06335-11

6. Cherry JD. Epidemic pertussis in 2012-the resurgence of a vaccine-preventable disease. $N$ Engl $J$ Med. (2012) 367:785-7. doi: 10.1056/NEJMp1209051

7. Zinkernagel RM. What if protective immunity is antigen-driven and not due to so-called memory B and T cells? Immunol Rev. (2018) 283:238-46. doi: $10.1111 /$ imr.12648

8. Näslund C. Resultats des Experiences de Vaccination par le BCG Poursuivies dans le Norrbotten (Suède) (Septembre 1927-Décembre 1931). Vaccination Preventative de Tuberculose, Rapports et Documents. Paris: Institut Pasteur (1932).

9. Aaby P, Roth A, Ravn H, Napirna BM, Rodrigues A, Lisse IM, et al. Randomized trial of BCG vaccination at birth to low-birth-weight children: 
beneficial nonspecific effects in the neonatal period? J Infect Dis. (2011) 204:245-52. doi: 10.1093/infdis/jir240

10. Benn CS, Netea MG, Selin LK, Aaby P. A small jab - a big effect: nonspecific immunomodulation by vaccines. Trends Immunol. (2013) 34:431-9. doi: 10.1016/j.it.2013.04.004

11. Goodridge HS, Ahmed SS, Curtis N, Kollmann TR, Levy O, Netea MG, et al. Harnessing the beneficial heterologous effects of vaccination. Nat Rev Immunol. (2016) 16:392-400. doi: 10.1038/nri.2016.43

12. Mayr A. Taking advantage of the positive side-effects of smallpox vaccination. J Vet Med B Infect Dis Vet Public Health (2004) 51:199-201. doi: 10.1111/j.1439-0450.2004.00763.x

13. Netea MG, Quintin J, van der Meer JW. Trained immunity: a memory for innate host defense. Cell Host Microbe (2011) 9:355-61. doi: 10.1016/j.chom.2011.04.006

14. Quintin J, Saeed S, Martens JHA, Giamarellos-Bourboulis EJ, Ifrim DC, Logie C, et al. Candida albicans infection affords protection against reinfection via functional reprogramming of monocytes. Cell Host Microbe (2012) 12:22332. doi: $10.1016 /$ j.chom.2012.06.006

15. Sun JC, Ugolini S, Vivier E. Immunological memory within the innate immune system. EMBO J. (2014) 33:1295-303. doi: 10.1002/embj.201387651

16. Gourbal B, Pinaud S, Beckers GJM, Van Der Meer JWM, Conrath U, Netea MG. Innate immune memory: an evolutionary perspective. Immunol Rev. (2018) 283:21-40. doi: 10.1111/imr.12647

17. Quintin J, Cheng SC, van der Meer JW, Netea MG. Innate immune memory: towards a better understanding of host defense mechanisms. Curr Opin Immunol. (2014) 29:1-7. doi: 10.1016/j.coi.2014.02.006

18. Saeed S, Quintin J, Kerstens HH, Rao NA, Aghajanirefah A, Matarese $\mathrm{F}$, et al. Epigenetic programming of monocyte-to-macrophage differentiation and trained innate immunity. Science (2014) 345:1251086. doi: $10.1126 /$ science. 1251086

19. Netea MG, Joosten LA, Latz E, Mills KH, Natoli G, Stunnenberg HG, et al. Trained immunity: a program of innate immune memory in health and disease. Science (2016) 352:aaf1098. doi: 10.1126/science.aaf1098

20. Dominguez-Andres J, Joosten LA, Netea MG. Induction of innate immune memory: the role of cellular metabolism. Curr Opin Immunol. (2018) 56:106. doi: 10.1016/j.coi.2018.09.001

21. Cheng SC, Quintin J, Cramer RA, Shepardson KM, Saeed S, Kumar V, et al. mTOR- and HIF-1alpha-mediated aerobic glycolysis as metabolic basis for trained immunity. Science (2014) 345:1250684. doi: 10.1126/science.1250684

22. Arts RJW, Carvalho A, La Rocca C, Palma C, Rodrigues F, Silvestre R, et al. Immunometabolic pathways in BCG-induced trained immunity. Cell Rep. (2016) 17:2562-71. doi: 10.1016/j.celrep.2016.11.011

23. Gruenbacher G, Thurnher M. Mevalonate metabolism in cancer stemness and trained immunity. Front Oncol. (2018) 8:394. doi: $10.3389 /$ fonc. 2018.00394

24. Kleinnijenhuis J, Quintin J, Preijers F, Joosten LA, Ifrim DC, Saeed S, et al. Bacille Calmette-Guerin induces NOD2-dependent nonspecific protection from reinfection via epigenetic reprogramming of monocytes. Proc Natl Acad Sci USA. (2012) 109:17537-42. doi: 10.1073/pnas.1202870109

25. Arts RJW, Moorlag S, Novakovic B, Li Y, Wang SY, Oosting M, et al. BCG vaccination protects against experimental viral infection in humans through the induction of cytokines associated with trained immunity. Cell Host Microbe (2018b) 23:89-100e5. doi: 10.1016/j.chom.2017.12.010

26. Kleinnijenhuis J, Quintin J, Preijers F, Benn CS, Joosten LA, Jacobs C, et al. Long-lasting effects of BCG vaccination on both heterologous Th1/Th17 responses and innate trained immunity. J Innate Immun. (2014) 6:152-8. doi: $10.1159 / 000355628$

27. Faure F, Jouve M, Lebhar-Peguillet I, Sadaka C, Sepulveda F, Lantz O, et al. Blood monocytes sample MelanA/MART1 antigen for long-lasting crosspresentation to $\mathrm{CD} 8(+) \mathrm{T}$ cells after differentiation into dendritic cells. Int $\mathrm{J}$ Cancer (2018) 142:133-44. doi: 10.1002/ijc.31037

28. Kaufmann E, Sanz J, Dunn JL, Khan N, Mendonca LE, Pacis A, et al. BCG educates hematopoietic stem cells to generate protective innate immunity against tuberculosis. Cell (2018) 172:176-190e.19. doi: 10.1016/j.cell.2017.12.031

29. Breyne K, Steenbrugge J, Demeyere K, Vanden Berghe T, Meyer E. Preconditioning with lipopolysaccharide or lipoteichoic acid protects against
Staphylococcus aureus mammary infection in mice. Front Immunol. (2017) 8:833. doi: 10.3389/fimmu.2017.00833

30. Krahenbuhl JL, Sharma SD, Ferraresi RW, Remington JS. Effects of muramyl dipeptide treatment on resistance to infection with Toxoplasma gondii in mice. Infect Immun. (1981) 31:716-22.

31. Munoz N, Van Maele L, Marques JM, Rial A, Sirard JC, Chabalgoity JA. Mucosal administration of flagellin protects mice from Streptococcus pneumoniae lung infection. Infect Immun. (2010) 78:4226-33. doi: 10.1128/IAI.00224-10

32. Zhang B, Chassaing B, Shi Z, Uchiyama R, Zhang Z, Denning TL, et al. Viral infection. Prevention and cure of rotavirus infection via TLR5/NLRC4mediated production of IL-22 and IL-18. Science (2014) 346:861-65. doi: $10.1126 /$ science. 1256999

33. Abdul-Careem MF, Firoz Mian M, Gillgrass AE, Chenoweth MJ, Barra NG, Chan T, et al. FimH, a TLR4 ligand, induces innate antiviral responses in the lung leading to protection against lethal influenza infection in mice. Antiviral Res. (2011) 92:346-55. doi: 10.1016/j.antiviral.2011.09.004

34. Marakalala MJ, Williams DL, Hoving JC, Engstad R, Netea MG, Brown GD. Dectin-1 plays a redundant role in the immunomodulatory activities of beta-glucan-rich ligands in vivo. Microbes Infect. (2013) 15:511-5. doi: 10.1016/j.micinf.2013.03.002

35. Rizzetto L, Ifrim DC, Moretti S, Tocci N, Cheng SC, Quintin J, et al. Fungal chitin induces trained immunity in human monocytes during cross-talk of the host with Saccharomyces cerevisiae. J Biol Chem. (2016) 291:7961-72. doi: 10.1074/jbc.M115.699645

36. Ribes S, Meister T, Ott M, Redlich S, Janova H, Hanisch UK, et al. Intraperitoneal prophylaxis with $\mathrm{CpG}$ oligodeoxynucleotides protects neutropenic mice against intracerebral Escherichia coli K1 infection. $J$ Neuroinflammation (2014) 11:14. doi: 10.1186/1742-2094-11-14

37. Jiang $\mathrm{T}$, Zhao $\mathrm{H}$, Li XF, Deng YQ, Liu J, Xu LJ, et al. CpG oligodeoxynucleotides protect against the $2009 \mathrm{H} 1 \mathrm{~N} 1$ pandemic influenza virus infection in a murine model. Antiviral Res. (2011) 89:124-6. doi: 10.1016/j.antiviral.2010.11.013

38. Norton EB, Clements JD, Voss TG, Cardenas-Freytag L. Prophylactic administration of bacterially derived immunomodulators improves the outcome of influenza virus infection in a murine model. J Virol. (2010) 84:2983-95. doi: 10.1128/JVI.01805-09

39. Schleicher U, Paduch K, Debus A, Obermeyer S, Konig T, Kling JC, et al. TNF-mediated restriction of arginase 1 expression in myeloid cells triggers type 2 no synthase activity at the site of infection. Cell Rep. (2016) 15:106275. doi: 10.1016/j.celrep.2016.04.001

40. Mayer-Barber KD, Yan B. Clash of the cytokine titans: counter-regulation of interleukin-1 and type I interferon-mediated inflammatory responses. Cell Mol Immunol. (2017) 14:22-35. doi: 10.1038/cmi.2016.25

41. Tejera-Alhambra M, Palomares O, Perez de Diego R, Diaz-Lezcano I, Sanchez-Ramon S. New biological insights in the immunomodulatory effects of mucosal polybacterial vaccines in clinical practice. Curr Pharm Des. (2016) 22:6283-93. doi: 10.2174/1381612822666160829 143129

42. Mourits VP, Wijkmans JC, Joosten LA, Netea MG. Trained immunity as a novel therapeutic strategy. Curr Opin Pharmacol. (2018) 41:52-8. doi: 10.1016/j.coph.2018.04.007

43. Tso GHW, Reales-Calderon JA, Pavelka N. The elusive anti-candida vaccine: lessons from the past and opportunities for the future. Front Immunol. (2018) 9:897. doi: 10.3389/fimmu.2018.00897

44. Guy B. The perfect mix: recent progress in adjuvant research. Nat Rev Microbiol. (2007) 5:505-17. doi: 10.1038/nrmicro1681

45. Blok BA, Arts RJ, van Crevel R, Benn CS, Netea MG. Trained innate immunity as underlying mechanism for the long-term, nonspecific effects of vaccines. J Leukoc Biol. (2015) 98:347-56. doi: 10.1189/jlb.5RI0315-096R

46. de Bree C, Koeken V, Joosten LAB, Aaby P, Benn CS, van Crevel R, et al. Non-specific effects of vaccines: current evidence and potential implications. Semin Immunol. (2018). 39:35-43 doi: 10.1016/j.smim.2018.06.002

47. Cirauqui C, Benito-Villalvilla C, Sanchez-Ramon S, Sirvent S, Diez-Rivero $\mathrm{CM}$, Conejero L, et al. Human dendritic cells activated with MV130 induce Th1, Th17 and IL-10 responses via RIPK2 and MyD88 signalling pathways. Eur J Immunol. (2018) 48:180-93. doi: 10.1002/eji.201747024 
48. Zanoni I, Tan Y, Di Gioia M, Broggi A, Ruan J, Shi J, et al. An endogenous caspase-11 ligand elicits interleukin-1 release from living dendritic cells. Science (2016) 352:1232-6. doi: 10.1126/science.aaf3036

49. Evavold CL, Kagan JC. How inflammasomes inform adaptive immunity. $J$ Mol Biol. (2018) 430:217-37. doi: 10.1016/j.jmb.2017.09.019

50. Mitroulis I, Ruppova K, Wang B, Chen LS, Grzybek M, Grinenko T, et al. Modulation of myelopoiesis progenitors is an integral component of trained immunity. Cell (2018) 172:147-61.e12. doi: 10.1016/j.cell.2017.11.034

51. Alecsandru D, Valor L, Sanchez-Ramon S, Gil J, Carbone J, Navarro J, et al. Sublingual therapeutic immunization with a polyvalent bacterial preparation in patients with recurrent respiratory infections: immunomodulatory effect on antigen-specific memory CD4+ T cells and impact on clinical outcome. Clin Exp Immunol. (2011) 164:100-7. doi: 10.1111/j.1365-2249.2011.04320.x

52. Lorenzo-Gomez MF, Padilla-Fernandez B, Garcia-Criado FJ, Miron-Canelo JA, Gil-Vicente A, Nieto-Huertos A, et al. Evaluation of a therapeutic vaccine for the prevention of recurrent urinary tract infections versus prophylactic treatment with antibiotics. Int Urogynecol J. (2013) 24:127-34. doi: 10.1007/s00192-012-1853-5

53. Lorenzo-Gomez MF, Padilla-Fernandez B, Garcia-Cenador MB, VirsedaRodriguez AJ, Martin-Garcia I, Sanchez-Escudero A, et al. Comparison of sublingual therapeutic vaccine with antibiotics for the prophylaxis of recurrent urinary tract infections. Front Cell Infect Microbiol. (2015) 5:50. doi: $10.3389 /$ fcimb. 2015.00050

54. Sanchez-Ramon S, Perez de Diego R, Dieli-Crimi R, Subiza JL. Extending the clinical horizons of mucosal bacterial vaccines: current evidence and future prospects. Curr Drug Targets (2014) 15:1132-43. doi: $10.2174 / 1389450115666141020160705$

55. Yang B, Foley S. First experience in the UK of treating women with recurrent urinary tract infections with the bacterial vaccine Uromune((R)). BJU Int. (2018) 121:289-92. doi: 10.1111/bju.14067

56. Benito-Villalvilla C, Cirauqui C, Diez-Rivero CM, Casanovas M, Subiza JL, Palomares O. MV140, a sublingual polyvalent bacterial preparation to treat recurrent urinary tract infections, licenses human dendritic cells for generating Th1, Th17, and IL-10 responses via Syk and MyD88. Mucosal Immunol. (2017) 10:924-35. doi: 10.1038/mi.2016.112

57. Birk NM, Nissen TN, Kjaergaard J, Hartling HJ, Thostesen LM, Kofoed PE, et al. Effects of Bacillus Calmette-Guerin (BCG) vaccination at birth on $\mathrm{T}$ and B lymphocyte subsets: results from a clinical randomized trial. Sci Rep. (2017) 7:12398. doi: 10.1038/s41598-017-11601-6

58. Jensen KJ, Benn CS, van Crevel R. Unravelling the nature of nonspecific effects of vaccines-A challenge for innate immunologists. Semin Immunol. (2016) 28:377-83. doi: 10.1016/j.smim.2016. 05.005

59. Kjaergaard J, Birk NM, Nissen TN, Thostesen LM, Pihl GT, Benn CS, et al. Nonspecific effect of BCG vaccination at birth on early childhood infections: a randomized, clinical multicenter trial. Pediatr Res. (2016) 80:681-5. doi: 10.1038/pr.2016.142

60. de Bree C, Marijnissen RJ, Kel JM, Rosendahl Huber SK, Aaby P, Benn CS, et al. (2018). Bacillus Calmette-guerin-induced trained immunity is not protective for experimental influenza A/Anhui/1/2013 (H7N9) infection in mice. Front Immunol. 9:869. doi: 10.3389/fimmu.2018.00869

61. Kawai K, Miyazaki J, Joraku A, Nishiyama H, Akaza H. Bacillus CalmetteGuerin (BCG) immunotherapy for bladder cancer: current understanding and perspectives on engineered BCG vaccine. Cancer Sci. (2013) 104:22-7. doi: $10.1111 /$ cas. 12075

62. Buffen K, Oosting M, Quintin J, Ng A, Kleinnijenhuis J, Kumar V, et al. Autophagy controls BCG-induced trained immunity and the response to intravesical BCG therapy for bladder cancer. PLoS Pathog. (2014) 10:e1004485. doi: 10.1371/journal.ppat.1004485

63. Pieraerts C, Martin V, Jichlinski P, Nardelli-Haefliger D, Derre L. Detection of functional antigen-specific $\mathrm{T}$ cells from urine of non-muscle invasive bladder cancer patients. Oncoimmunology (2012) 1:694-8. doi: 10.4161/onci. 20526

64. Chamberlain RS, Kaufman H. Innovations and strategies for the development of anticancer vaccines. Expert Opin Pharmacother. (2000) 1:603-14. doi: 10.1517/14656566.1.4.603

65. Aaby P, Gustafson P, Roth A, Rodrigues A, Fernandes M, Sodemann $\mathrm{M}$, et al. Vaccinia scars associated with better survival for adults.
An observational study from Guinea-Bissau. Vaccine (2006) 24:5718-25. doi: 10.1016/j.vaccine.2006.04.045

66. Jensen ML, Dave S, Schim van der Loeff $M$, da Costa C, Vincent T, Leligdowicz A, et al. Vaccinia scars associated with improved survival among adults in rural Guinea-Bissau. PLoS ONE (2006) 1:e101. doi: 10.1371/journal.pone.0000101

67. Gillard GO, Bivas-Benita M, Hovav AH, Grandpre LE, Panas MW, Seaman MS, et al. Thyl+ NK [corrected] cells from vaccinia virusprimed mice confer protection against vaccinia virus challenge in the absence of adaptive lymphocytes. PLoS Pathog. (2011) 7:e1002141. doi: 10.1371/journal.ppat.1002141

68. Piedra PA, Gaglani MJ, Kozinetz CA, Herschler GB, Fewlass C, Harvey D, et al. Trivalent live attenuated intranasal influenza vaccine administered during the 2003-2004 influenza type A (H3N2) outbreak provided immediate, direct, and indirect protection in children. Pediatrics (2007) 120:e553-64. doi: 10.1542/peds.2006-2836

69. Diebold SS, Kaisho T, Hemmi H, Akira S, Reis e Sousa C. Innate antiviral responses by means of TLR7-mediated recognition of single-stranded RNA. Science (2004) 303:1529-31. doi: 10.1126/science.1093616

70. Guillot L, Le Goffic R, Bloch S, Escriou N, Akira S, Chignard M, et al. Involvement of toll-like receptor 3 in the immune response of lung epithelial cells to double-stranded RNA and influenza A virus. J Biol Chem. (2005) 280:5571-80. doi: 10.1074/jbc.M410592200

71. Lee YJ, Lee JY, Jang YH, Seo SU, Chang J, Seong BL. Non-specific effect of vaccines: immediate protection against respiratory syncytial virus infection by a live attenuated influenza vaccine. Front Microbiol. (2018) 9:83. doi: $10.3389 /$ fmicb. 2018.00083

72. Bistoni F, Vecchiarelli A, Cenci E, Puccetti P, Marconi P, Cassone A. Evidence for macrophage-mediated protection against lethal Candida albicans infection. Infect Immun. (1986) 51:668-74.

73. Brown GD, Gordon S. Fungal beta-glucans and mammalian immunity. Immunity (2003) 19:311-5. doi: 10.1016/S1074-7613(03)00233-4

74. Leentjens J, Quintin J, Gerretsen J, Kox M, Pickkers P, Netea MG. The effects of orally administered Beta-glucan on innate immune responses in humans, a randomized open-label intervention pilot-study. PLOS ONE (2014) 9:e108794. doi: 10.1371/journal.pone.0108794

75. Pasquali C, Salami O, Taneja M, Gollwitzer ES, Trompette A, Pattaroni $\mathrm{C}$, et al. Enhanced mucosal antibody production and protection against respiratory infections following an orally administered bacterial extract. Front Med. (2014) 1:41. doi: 10.3389/fmed.2014.00041

76. Roth M, Pasquali C, Stolz D, Tamm M. Broncho Vaxom (OM-85) modulates rhinovirus docking proteins on human airway epithelial cells via Erk1/2 mitogen activated protein kinase and cAMP. PLOS ONE (2017) 12:e0188010. doi: 10.1371/journal.pone.0188010

77. Bessler WG, Vor dem Esche U, Masihi N. The bacterial extract OM$85 \mathrm{BV}$ protects mice against influenza and Salmonella infection. Int Immunopharmacol. (2010) 10:1086-90. doi: 10.1016/j.intimp.2010.06.009

78. Collet JP, Shapiro P, Ernst P, Renzi T, Ducruet T, Robinson A. Effects of an immunostimulating agent on acute exacerbations and hospitalizations in patients with chronic obstructive pulmonary disease. The PARI-IS study steering committee and research group prevention of acute respiratory infection by an immunostimulant. Am J Respir Crit Care Med. (1997) 156:1719-24. doi: 10.1164/ajrccm.156.6.9612096

79. Gutierrez-Tarango MD, Berber A. Safety and efficacy of two courses of OM$85 \mathrm{BV}$ in the prevention of respiratory tract infections in children during 12 months. Chest (2001) 119:1742-8. doi: 10.1378/chest.119.6.1742

80. Razi CH, Harmanci K, Abaci A, Ozdemir O, Hizli S, Renda R, et al. The immunostimulant OM-85 BV prevents wheezing attacks in preschool children. J Allergy Clin Immunol. (2010) 126:763-9. doi: 10.1016/j.jaci.2010.07.038

81. Scheid A, Borriello F, Pietrasanta C, Christou H, Diray-Arce J, Pettengill MA, et al. Adjuvant effect of bacille calmette-guerin on hepatitis B vaccine immunogenicity in the preterm and term newborn. Front Immunol. (2018) 9:29. doi: 10.3389/fimmu.2018.00029

82. Ota MO, Vekemans J, Schlegel-Haueter SE, Fielding K, Sanneh M, Kidd $\mathrm{M}$, et al. Influence of Mycobacterium bovis bacillus Calmette-Guerin on antibody and cytokine responses to human neonatal vaccination. J Immunol. (2002) 168:919-25. doi: 10.4049/jimmunol.168.2.919 
83. Mizgerd JP. Lung infection-a public health priority. PLoS Med. (2006) 3:e76. doi: 10.1371/journal.pmed.0030076

84. Foxman B. The epidemiology of urinary tract infection. Nat Rev Urol. (2010) 7:653-60. doi: 10.1038/nrurol.2010.190

85. Chien YW, Klugman KP, Morens DM. Efficacy of whole-cell killed bacterial vaccines in preventing pneumonia and death during the 1918 influenza pandemic. J Infect Dis. (2010) 202:1639-48. doi: 10.1086/657144

86. Kloepfer KM, Lee WM, Pappas TE, Kang TJ, Vrtis RF, Evans MD, et al. Detection of pathogenic bacteria during rhinovirus infection is associated with increased respiratory symptoms and asthma exacerbations. J Allergy Clin Immunol. (2014) 133:1301-7, 1307.e1-3. doi: 10.1016/j.jaci.2014.02.030

87. Ndung'u T, Weiss RA. On HIV diversity. AIDS (2012) 26:1255-60. doi: 10.1097/QAD.0b013e32835461b5

88. Kumar A, Meldgaard TS, Bertholet S. Novel platforms for the development of a universal influenza vaccine. Front Immunol. (2018) 9:600. doi: 10.3389/fimmu.2018.00600

89. Pichichero ME. Pneumococcal whole-cell and protein-based vaccines: changing the paradigm. Expert Rev Vaccines (2017) 16:1181-90. doi: 10.1080/14760584.2017.1393335

90. Kline KA, Bowdish DM. Infection in an aging population. Curr Opin Microbiol. (2016) 29:63-7. doi: 10.1016/j.mib.2015.11.003

91. Esposito S, Soto-Martinez ME, Feleszko W, Jones MH, Shen KL, Schaad UB. Nonspecific immunomodulators for recurrent respiratory tract infections, wheezing and asthma in children: a systematic review of mechanistic and clinical evidence. Curr Opin Allergy Clin Immunol. (2018) 18:198-209. doi: 10.1097/ACI.0000000000000433

92. Wilson R, Sethi S, Anzueto A, Miravitlles M. Antibiotics for treatment and prevention of exacerbations of chronic obstructive pulmonary disease. $J$ Infect. (2013) 67:497-515. doi: 10.1016/j.jinf.2013.08.010

93. Abzug MJ. Acute sinusitis in children: do antibiotics have any role? J Infect. (2014) 68(Suppl 1):S33-7. doi: 10.1016/j.jinf.2013.09.012

94. Novakovic B, Habibi E, Wang SY, Arts RJW, Davar R, Megchelenbrink W, et al. Beta-glucan reverses the epigenetic state of LPS-induced immunological tolerance. Cell (2016) 167:1354-68.e14. doi: 10.1016/j.cell.2016.09.034

95. Leentjens J, Bekkering S, Joosten LAB, Netea MG, Burgner DP, Riksen NP. Trained innate immunity as a novel mechanism linking infection and the development of atherosclerosis. Circ Res. (2018) 122:664-9. doi: 10.1161/CIRCRESAHA.117.312465

96. Hoogeveen RM, Nahrendorf M, Riksen NP, Netea MG, de Winther MPJ, Lutgens E, et al. Monocyte and haematopoietic progenitor reprogramming as common mechanism underlying chronic inflammatory and cardiovascular diseases. Eur Heart J. (2017) 39:3521-7. doi: 10.1093/eurheartj/ehx581

97. Crisan TO, Netea MG, Joosten LA. Innate immune memory: Implications for host responses to damage-associated molecular patterns. Eur J Immunol. (2016) 46:817-28. doi: 10.1002/eji.201545497

98. Arts RJW, Joosten LAB, Netea MG. The potential role of trained immunity in autoimmune and autoinflammatory disorders. Front Immunol. (2018a) 9:298. doi: 10.3389/fimmu.2018.00298
99. Wendeln AC, Degenhardt K, Kaurani L, Gertig M, Ulas T, Jain G, et al. Innate immune memory in the brain shapes neurological disease hallmarks. Nature (2018) 556:332-8. doi: 10.1038/s41586-018-0023-4

100. Chiavaroli C, Moore A. An hypothesis to link the opposing immunological effects induced by the bacterial lysate OM-89 in urinary tract infection and rheumatoid arthritis. BioDrugs (2006) 20:141-9. doi: 10.2165/00063030-200620030-00001

101. Toussirot E, Robinet E, Saas P, Chabod J, Auge B, Cozma G, et al. Bacterial extract (OM-89) specific and non specific immunomodulation in rheumatoid arthritis patients. Autoimmunity (2006) 39:299-306. doi: 10.1080/08916930600738425

102. Damfo SA, Reche P, Gatherer D, Flower DR. In silico design of knowledgebased Plasmodium falciparum epitope ensemble vaccines. J Mol Graph Model. (2017) 78:195-205. doi: 10.1016/j.jmgm.2017.10.004

103. Hegde NR, Gauthami S, Sampath Kumar HM, Bayry J. The use of databases, data mining and immunoinformatics in vaccinology: where are we? Expert Opin Drug Discov. (2018) 13:117-30. doi: 10.1080/17460441.2018.14 13088

104. Dowling DJ, Scott EA, Scheid A, Bergelson I, Joshi S, Pietrasanta C, et al. Toll-like receptor 8 agonist nanoparticles mimic immunomodulating effects of the live BCG vaccine and enhance neonatal innate and adaptive immune responses. J Allergy Clin Immunol. (2017) 140:1339-50. doi: 10.1016/j.jaci.2016.12.985

105. Bekkering S, Arts RJW, Novakovic B, Kourtzelis IC, van der Heijden CDCC, $\mathrm{Li}$ Y, et al. Metabolic induction of trained immunity through the mevalonate pathway. Cell (2018) 172:135-46.e9. doi: 10.1016/j.cell.2017.11.025

106. Christ A, Gunther P, Lauterbach MAR, Duewell P, Biswas D, Pelka K, et al. Western diet triggers NLRP3-dependent innate immune reprogramming. Cell (2018) 172:162-175.e14. doi: 10.1016/j.cell.2017.12.013

Conflict of Interest Statement: JS is the CEO of Inmunotek SL, a pharmaceutical company that manufactures bacterial vaccines. LC is an employee of Inmunotek. SS-R, DS, and ÓP have received research grants from Inmunotek.

The handling Editor declared a shared affiliation, though no other collaboration, with two of the authors OP and SS-R.

The remaining author declares that the research was conducted in the absence of any commercial or financial relationships that could be construed as a potential conflict of interest.

Copyright (C) 2018 Sánchez-Ramón, Conejero, Netea, Sancho, Palomares and Subiza. This is an open-access article distributed under the terms of the Creative Commons Attribution License (CC BY). The use, distribution or reproduction in other forums is permitted, provided the original author(s) and the copyright owner(s) are credited and that the original publication in this journal is cited, in accordance with accepted academic practice. No use, distribution or reproduction is permitted which does not comply with these terms. 